\title{
AKR1B10 promotes breast cancer metastasis through integrin a5/ס-catenin mediated FAK/Src/Rac1 signaling pathway
}

\author{
Chenfei Huang ${ }^{1}$, Steven Verhulst ${ }^{1}, \mathrm{Yi}_{\text {Shen }}{ }^{1}$, Yiwen Bu${ }^{1}, \mathrm{Yu} \mathrm{CaO}^{1}$, Yingchun $\mathrm{He}^{1,2}$, \\ Yuhong Wang, ${ }^{2}$ Dan Huang ${ }^{2}$, Chun $\mathrm{Cai}^{2}$, Krishna Rao ${ }^{1}$, Duan-Fang Liao ${ }^{2}$, Junfei \\ Jin ${ }^{3}$, Deliang $\mathrm{CaO}^{1,2}$ \\ ${ }^{1}$ Department of Medical Microbiology, Immunology \& Cell Biology, Simmons Cancer Institute, Southern Illinois University \\ School of Medicine, Springfield, IL 62794, USA \\ ${ }^{2}$ Division of Stem Cell Regulation and Application, State Key Laboratory of Chinese Medicine Powder and Medicine Innovation \\ in Hunan (incubation), Hunan University of Chinese Medicine, Changsha, Hunan 410208, China \\ ${ }^{3}$ China-USA Lipids in Health and Disease Research Center, Guilin Medical University, Guilin, 541001, Guangxi, China \\ Correspondence to: Deliang Cao, email: dcao@siumed.edu \\ Junfei Jin, email: changliangzijin@163.com
}

Keywords: AKR1B10, breast cancer metastasis, integrin a5, $\delta$-catenin, Racl

Received: March 18, 2016

Accepted: April 29, 2016

Published: May 27, 2016

\section{ABSTRACT}

Aldo-keto reductase 1B10 (AKR1B10) is not expressed in normal breast, but upregulated in primary and metastatic breast cancers, being a negative prognostic factor. This study characterized the molecular mechanisms of AKR1B10-promoted breast cancer metastasis. Ectopic expression of AKR1B10 in breast cancer cells MCF-7 and MDA-MB-231 or siRNA-mediated silencing in BT-20 cells affected cell adhesion, migration and invasion in cell culture, and metastasis to the lung in the nude mice through upregulation of integrin $a 5$ and $\delta$-catenin. Silencing of integrin a5 or $\delta$-catenin eradicated the cell adhesion and migration enhanced by AKR1B10, both of which acted synergistically. In these cells, the integrin a5 mediated focal adhesion kinase (FAK) signaling pathway was activated by AKR1B10, which, along with $\delta$-catenin, stimulated Rac1-mediated cell migration and movement. In human primary and lymph node metastatic breast cancer, AKR1B10, integrin a5 and $\delta$-catenin were correlatively upregulated with $r=0.645(p<0.0001)$ and $r=0.796(p<0.0001)$, respectively. These data suggest that AKR1B10 promotes breast cancer metastasis through activation of the integrin a5 and $\delta$-catenin mediated FAK/Src/Rac1 signaling pathway.

\section{INTRODUCTION}

Breast cancer (BC) accounts for approximately 40,000 deaths annually in the United States, and metastasis is the main cause of cancer mortality $[1,2]$. Cancer metastasis is a multistep process that includes tumor cell adhesion to extracellular matrix (ECM), migration and invasion, intravasation into the circulatory system, and extravasation to distant tissues, eventually forming micrometastases [3]. The migration and invasion of tumor cells is utterly crucial in cancer metastasis. A tumor cell attaches to ECM and forms protrusions through focal adhesions (FA) at the leading edge; tractive force breaks the existing cell-ECM interactions at the trailing edge, allowing the cell to move forward [4]. Cell adhesion molecules (CAM) play a critical role in cell migration $[5,6]$. Integrins, a major class of CAM, are important components of FA. The integrin family consists of $18 \alpha$ - and $8 \beta$-glycoprotein subunits, forming at least 25 distinct heterodimeric receptors. They specifically recognize and bind to specific ECM molecules and bi-directionally transport signals across the cell membrane, sensing environmental changes [7]. Integrins regulate cell adhesion and motility through a FA signaling cascade [8]. The integrin $\alpha / \beta$ clusters bind to ECM ligands, activating focal adhesion kinase (FAK). The activated FAK autophosphorylates its own tyrosine-397 residue and recruits Src family kinases that activate downstream signaling effectors, such as Rac1 [7]. Rac1 is a Rho GTPase that is located at leading edge of a moving cell and regulates Scar/WAVE-mediated actin polymerization and lamellipodia formation [9].

Integrin $\alpha 5$ interacts with integrin $\beta 1$ to form a heterodimer, which functions with fibronectin as a ligand, regulating cell adhesion [10]. In human hepatocarcinoma cells, integrin $\alpha 5$ promotes cell adhesion and migration 
[11], and in breast cancer, integrin $\alpha 5$ is upregulated as an indicator of poor prognosis [12]. Blockage of integrin $\alpha 5 \beta 1$ function suppresses breast cancer cell proliferation and metastasis [13]. Delta-catenin is an armadillo protein that is primarily expressed in neurons, where it functions in cell morphogenesis and movement [14]. The $\delta$-catenin is upregulated in breast, lung and brain cancers, promoting tumorigenesis and metastasis [15].

Aldo-keto reductase $1 \mathrm{~B} 10$ (AKR1B10) is a multifunctional protein, identified primarily from human hepatocellular carcinoma (HCC) [16]. AKR1B10 can efficiently converts cytotoxic and carcinogenic $\alpha, \beta$-unsaturated carbonyl compounds into alcoholic forms with less toxicity, protecting the host cell from carbonyl damage [17-21]. AKR1B10 also promotes de novo fatty acid/lipid synthesis by stabilizing acetyl-CoA carboxylase- $\alpha$ (ACCA), a rate-limiting enzyme in the de novo fatty acid synthesis [22, 23]. In normal tissues, AKR1B10 is primarily expressed in the colon and small intestine and promotes epithelial cell proliferation regulating epithelial cell self-renewal $[16,24]$. Targeted disruption of $A K R 1 B 8$ (an ortholog of $A K R 1 B 10$ in mouse) leads to diminished proliferation and migration of epithelial cells and increased susceptibility to carbonyl and oxidative stress-induced DNA damage and tumorigenesis [25]. In tumors, AKR1B10 is upregulated in breast, liver and lung cancers, promoting tumor growth and progression [26-29]. Overall, AKR1B10 functions as a protector of cells against carbonyl damage and a promoter of cell proliferation; but its role in tumorigenesis is tissue-context dependent. In breast cancer, AKR1B10 is also upregulated in the metastatic $(78.0 \%)$ and recurrent $(87.5 \%)$ tumors, indicating its potential role in breast cancer metastasis and recurrence [27]. This study clarified the molecular mechanism of action that AKR1B10 promotes breast cancer metastasis.

\section{RESULTS}

\section{AKR1B10 promotes adhesion, migration and invasion of breast cancer cells}

AKR1B10 is upregulated in human breast cancer and correlates with lymph node metastasis [27]. The current study demonstrated that ectopic expression of AKR1B10 in breast cancer cells MCF-7 (Supplementary Figure S1A) enhanced cell adhesion to fibronectin or collagen-coated plates (Figure 1A, left panel), but not to gelatin or laminin-coated plates (Supplementary Figure S2A). Wound-healing assays showed that MCF7 cells with AKR1B10 expression migrated into and fully covered the wound areas within 48 hours in the fibronectin-coated plates, but vector control cells did not (Figure 1B). Boyden chamber assays showed that AKR1B10 expression enhanced the transmigration of MCF-7 cells through fibronectin-coated membrane
(Figure 1C, left) and invasion in Matrigel (Figure 1C, right) when compared to vector control cells. Similarly, ectopic expression of AKR1B10 in MDA-MB-231 cells (Supplementary Figure S1B) also enhanced their migration and invasion (Figure 1D). In contrast, silencing of AKR1B10 in breast cancer cells BT20 (Supplementary Figure S1C) markedly lowered down their adhesion to fibronectin or collagen-coated plates (Figure 1A, right panel), but not to laminin or gelatin-coated plates (Supplementary Figure S2B). The transmigration of BT-20 cells with silencing of AKR1B10 was decreased by 40-50\% (Figure 1E). These data suggest that AKR1B10 promotes adhesion, migration and invasion of breast cancer cells.

\section{AKR1B10 upregulates the expression of integrin $\alpha 5$ and $\delta$-catenin in breast cancer cells}

Cell movement is mediated by cell-matrix interactions; and CAMs play a critical role in this process [6]. Therefore, we explored the potential effects of AKR1B10 on the expression of CAMs and ECMs in MCF-7 cells using an Adhesion-RT ${ }^{2}$ Profiler PCR array that allows for a quantitative assessment of 84 CAM and ECM genes (Figure 2A and Supplementary Figure S3). Using qRT-PCR and Western blot, we further confirmed the upregulation of CTNND2 ( $\delta$-catenin), ITGA5 (integrin $\alpha 5)$ and FN1 (fibronectin) by AKR1B10 at both mRNA (Figure 2B) and protein levels (Figure 2C) in MCF-7 cells. Consistently, both $\delta$-catenin and integrin $\alpha 5$ were also upregulated by AKR1B10 in MDA-MB-231 cells (Figure 2C, middle). In contrast, silencing of AKR1B10 in the BT-20 cells lowered down mRNA (Figure 2B) and protein (Figure 2C) levels of $\delta$-catenin and integrin $\alpha 5$. Of note, the effects of AKR1B10 on CAM expression displayed a cellular difference. FN1, CLEC3B, MMP2, MMP8, TIMP2 and TIMP3 were upregulated in MCF7 cells by AKR1B10, but not notably affected in BT-20 cells by AKR1B10 silencing, suggesting a cell-context dependence. Nevertheless, AKR1B10 consistently upregulates the expression of $\delta$-catenin and integrin $\alpha 5$ in all tested breast cancer cells.

We further asked how AKR1B10 upregulates integrin $\alpha 5$ and $\delta$-catenin expression. The ERK signaling is a critical participant of focal adhesion assembly and disassembly [30]. We thus examined the activity of ERK signaling cascade and the effects on the expression of integrin $\alpha 5$ and $\delta$-catenin. As shown in Figure 2D, the phosphorylated c-Raf, MEK1/2 and ERK1/2 were increased in the MCF-7 and MDA-MB-231 cells with AKR1B10 expression, but decreased in the BT-20 cells with AKR1B10 silencing. Pharmacological inhibition of ERK signaling by MEK1 inhibitors PD98059 (10 $\mu \mathrm{M})$ and $\mathrm{U} 0126(10 \mu \mathrm{M})$ attenuated the expression of integrin $\alpha 5$ and $\delta$-catenin upregulated by AKR1B10 (Figure 2E). These data suggest that AKR1B10 regulates the expression 
A

i) MCF-7

Fibronectin

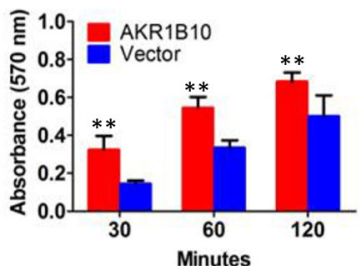

Collagen

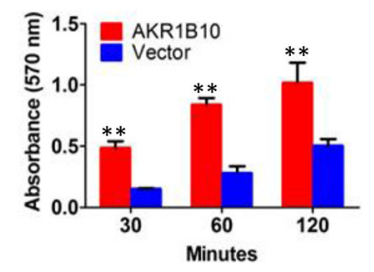

B
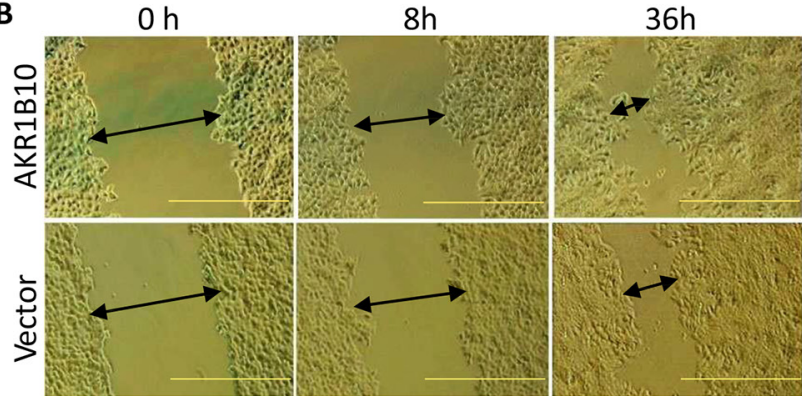

C
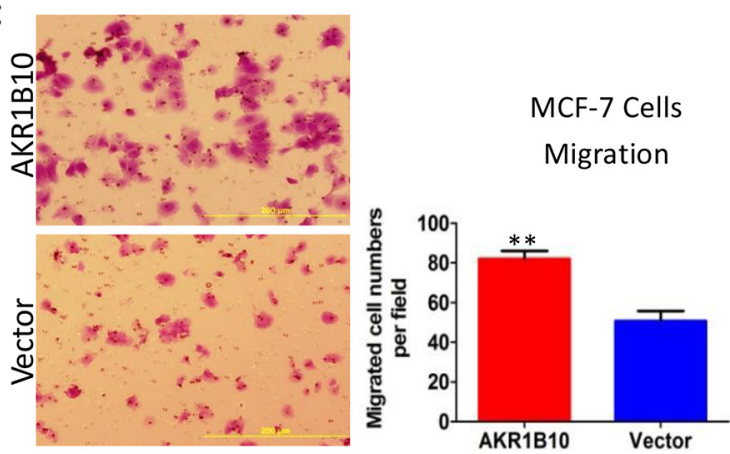

D

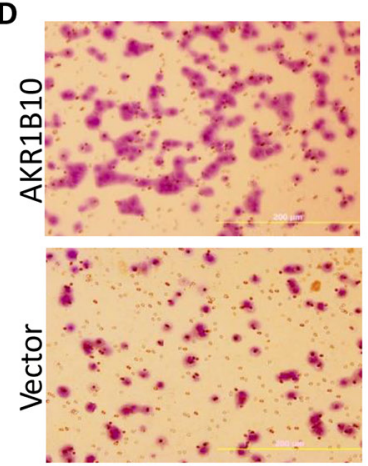

E
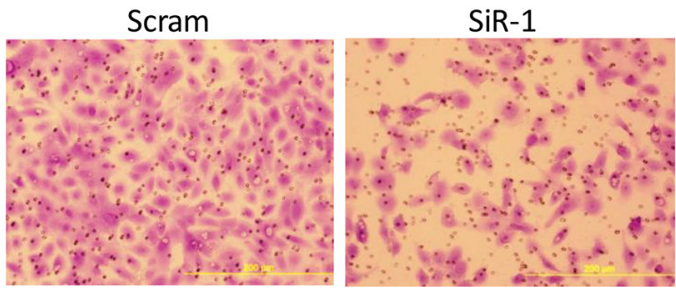

ii) $\mathrm{BT}-20$

Fibronectin

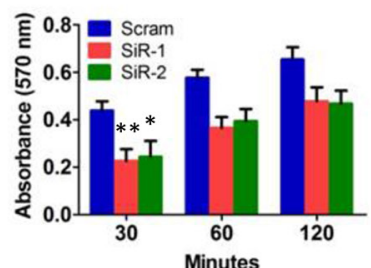

Collagen

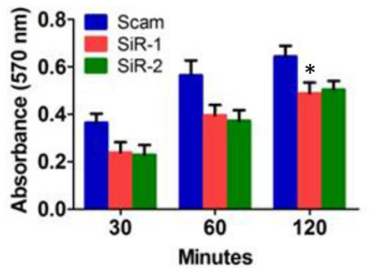

$48 \mathrm{~h}$
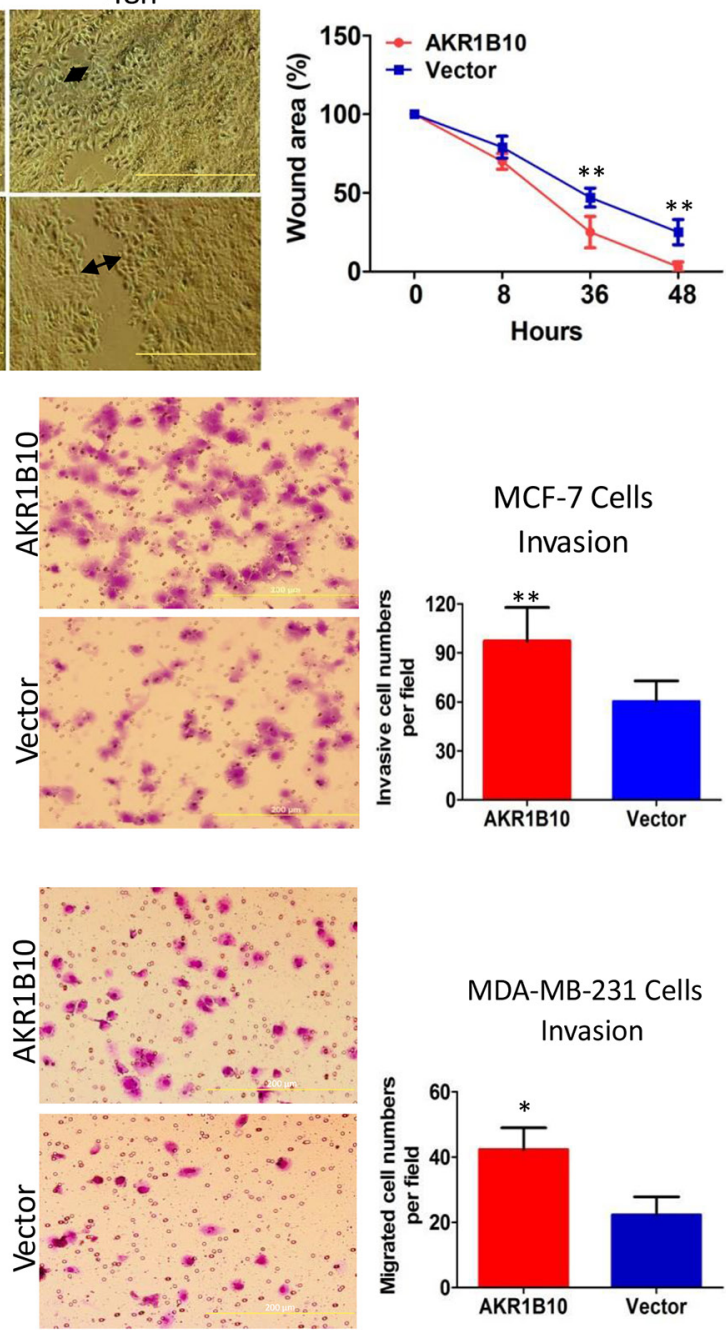

MDA-MB-231 Cells

Invasion

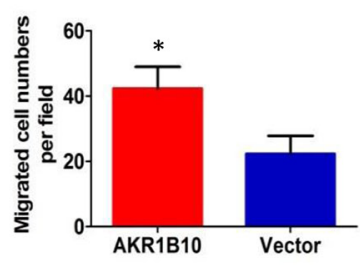

SiR-2
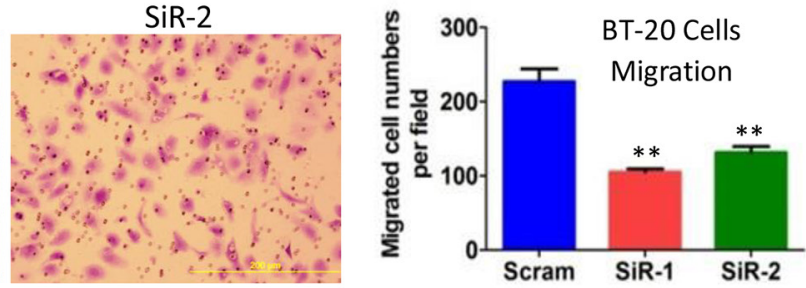

Figure 1: AKR1B10 increases adhesion, migration and invasion of breast cancer cells. AKR1B10 was ectopically expressed in MCF-7 and MDA-MB-231 cells, or silenced in BT-20 cells. A. Cell adhesion to fibronectin or collagen-coated plates. B. Wound-healing of MCF-7 cells. Scale bar $=500 \mu \mathrm{m}$. C. Transwell migration (left) and Boyden chamber invasion (right) of MCF-7 cells. D. Transwell migration (left) and Boyden chamber invasion (right) of MDA-MB-231 cells. E. Transwell migration of BT-20 cells. All data represent mean \pm SD from three independent experiments. *, $\mathrm{p}<0.05$ and ${ }^{* *}, \mathrm{p}<0.01$ compared to the vector control. Scram, scrambled siRNA; siR-1, AKR1B10 siRNA-1; and siR-2, AKR1B10 siRNA-2. 
A

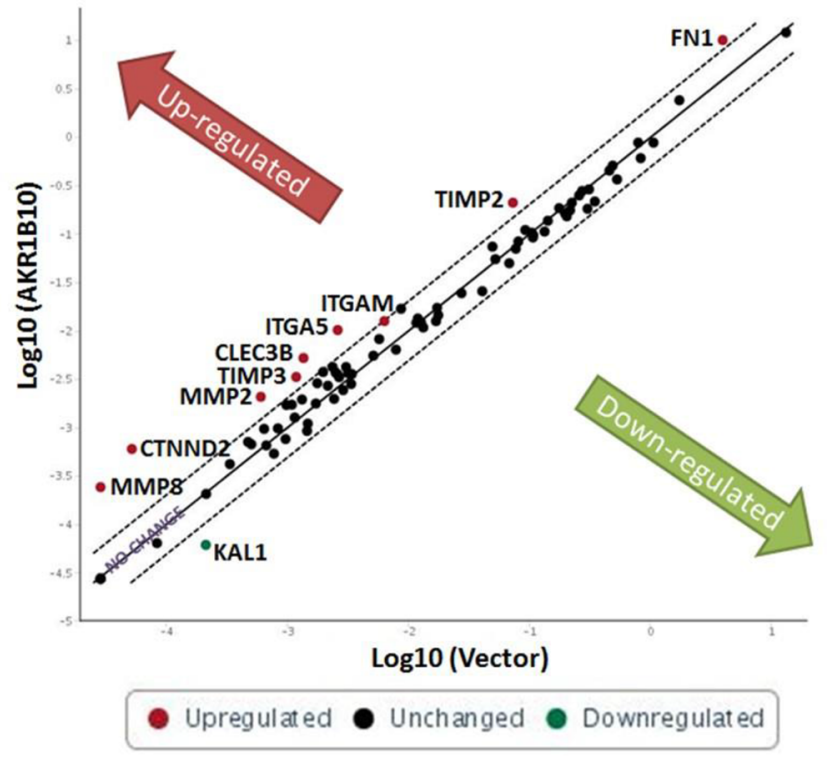

B i) MCF-7
C

i) MCF-7

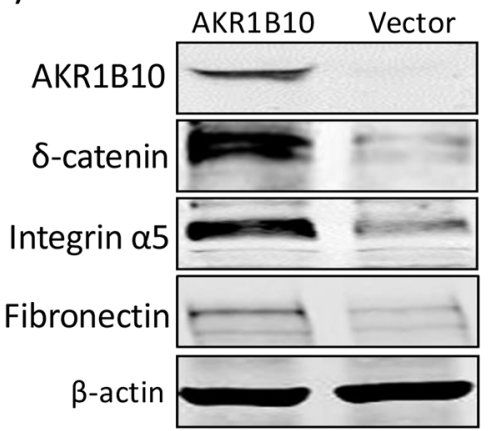

ii) MDA-MB-231

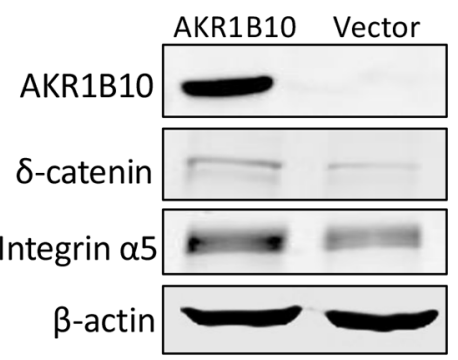

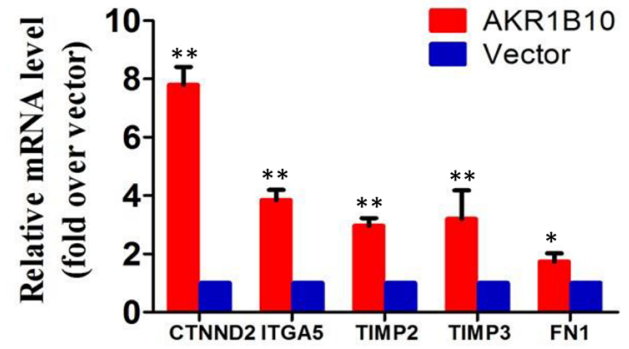

ii) BT-20

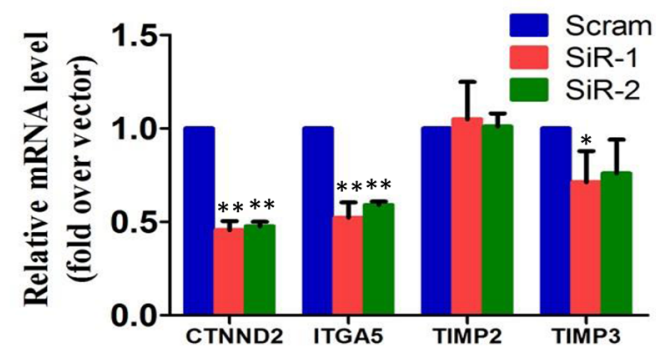

D

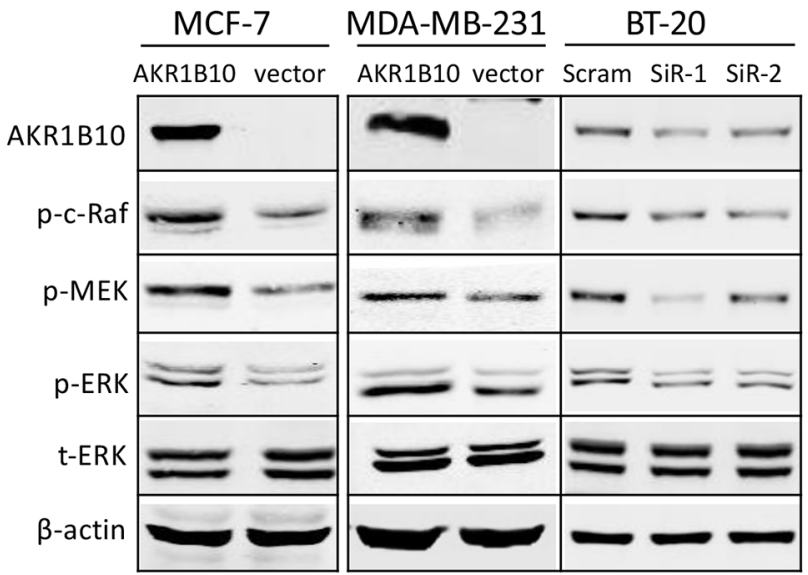

iii) BT-20

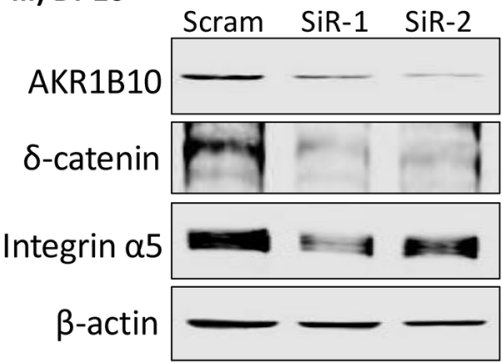

Figure 2: AKR1B10 upregulates integrin $\alpha 5$ and $\delta$-catenin in breast cancer cells. A. RT profiler PCR array results, showing expression of 84 cell adhesion molecules and extracellular proteins in MCF-7 cells with ectopic expression of AKR1B10. B. qRT-PCR and C. Western blot, confirming expression of interest genes in MCF-7, MDA-MB-231 and BT-20 cells. D. ERK signaling activation, showing p-Raf, p-MEK and p-ERK in MCF-7, MDA-MB-231 and BT-20 cells. E. Inhibition of integrin $\alpha 5$ and $\delta$-catenin expression by MEK1/2 inhibitors, PD98059 $(10 \mu \mathrm{M})$ and U0126 $(10 \mu \mathrm{M})$, showing expression of p-ERK1/2, integrin $\alpha 5$, and $\delta$-catenin in MCF-7 with ectopic AKR1B10 expression. 
of integrin $\alpha 5$ and $\delta$-catenin through the c-Raf/MEK/ERK signaling pathway.

\section{Integrin $\alpha 5$ and $\delta$-catenin mediate cell adhesion and migration through focal adhesion signaling cascade}

We further assessed the role of integrin $\alpha 5$ and $\delta$-catenin in the AKR1B10-enhanced adhesion and migration of breast cancer cells by gene silencing (Supplementary Figure S4). Our results showed that silencing of integrin $\alpha 5$ by siRNA in MCF-7 cells attenuated the AKR1B10-enhanced cell adhesion to fibronectin-coated plates (Figure 3A) and the transmigration in Boyden chambers (Figure 3B). Silencing of $\delta$-catenin also lowered down cell transmigration, but to a less content; and double silencing of both integrin $\alpha 5$ and $\delta$-catenin demonstrated a synergistic role in suppression of the cell transmigration (Figure 3B). These data suggest that AKR1B10 promotes the adhesion and migration of breast cancer cells through the integrin $\alpha 5$ and $\delta$-catenin mediated mechanism. The integrin $\alpha 5$ and $\delta$-catenin function synergistically in this process.

Integrins interact with ECM proteins and activate a focal adhesion-mediated signaling cascade to drive cell movement. This process involves the phosphorylation and activation of FAK, Src, paxillin and Rac1 [7]. We estimated the effects of AKR1B10 expression on the focal adhesion signaling cascade. As shown in Figure 4A (left panel), ectopic expression of AKR1B10 in the MCF-7 and MDA-MB-231cells enhanced the phosphoY397FAK level, but not the phospho-Y925/FAK. The Y397-phosphorylated FAK provides a platform for Src association and phosphorylation, which in turn activates downstream effectors Y118-paxillin (Figure 4A, left panel). In contrast, AKR1B10 silencing in BT-20 cells led to decrease in phospho-Y397 FAK, phosphoSrc and phospho-paxillin (Figure 4A, right panel). As a downstream effector of the FAK/Src/paxillin signaling, Rac1 promotes cell motility through cytoskeleton remodeling [31]. Using pull-down assays, we found that the Rac1 was activated in MCF-7 cells (Figure 4B, upper left). Pharmacological inhibition of the Rac1 activity by Ehop-016 attenuated the cell migration increased by AKR1B10 (Figure 4B). These data suggest that AKR1B10 promotes cell migration via the integrin $\alpha 5$ mediated focal adhesion signaling cascade. The Racl functions as a downstream effector in this process.

\section{AKR1B10 promotes lung metastasis of MDA- MB-231 cells}

To confirm the in vitro data that AKR1B10 promotes migration and invasion of breast cancer cells, we extended this study to animals. As shown in Figure 5, AKR1B10 promoted the lung metastasis of MDA-MB-231 cells as measured by the in vivo and lung ex vivo bioluminescent imaging. At the endpoint, mice were euthanized and the lungs were excised for histological analysis; and results showed that metastatic nodules were formed in lungs and larger in the MDA-MB-231 cells with AKR1B10 expression when compared to vector control cells. These data suggest that AKR1B10 promotes the lung metastasis and growth of breast cancer cells.

\section{AKR1B10, integrin $\alpha 5$, and $\delta$-catenin are correlatively upregulated in human primary and metastatic breast cancers}

To evaluate translational relevance of the study results, we further investigated the expression and correlations of AKR1B10, integrin $\alpha 5$ and $\delta$-catenin in human breast cancer tissues using adjacent sections of tissue microarrays. As shown in Figure 6 and Supplementary Figure S5, AKR1B10, integrin $\alpha 5$ and $\delta$-catenin were upregulated in breast cancers, particularly in the metastatic lymph nodes. Correlative analyses using Spearman correlation indicated that the expression of AKR1B10, integrin $\alpha 5$ and $\delta$-catenin was correlated to each other (Table 1); multivariate canonical correlations of AKR1B10, integrin $\alpha 5$ and $\delta$-catenin expression were $\mathrm{r}=0.645(\mathrm{p}<0.0001)$ in primary breast cancer and $\mathrm{r}=0.796$ $(\mathrm{p}<0.0001)$ in metastatic lymph nodes.

\section{DISCUSSION}

AKR1B10 is upregulated in multiple human tumors, including liver, lung, and breast cancers, functioning as a potential negative prognostic factor. However, little is known of the molecular mechanisms of action. This study demonstrated for the first time that AKR1B10 promoted breast cancer metastasis through activation of the integrin $\alpha 5$ and $\delta$-catenin mediated FAK/Src/Rac1 signaling pathway. This mechanism was dissected via in vitro cellular studies and confirmed in in vivo metastatic animal models and ex vivo human tissues. This discovery defines AKR1B10 as a new oncogenic factor in the growth and progression of breast cancer.

Ectopic expression of AKR1B10 in breast cancer cells promoted their adhesion to fibronectin and collagen, migration in fibronectin-coated plates and invasion in Matrigel. These are in consistence with the clinical settings where AKR1B10 expression correlates with lymph node metastasis and worse disease-free survival [27]. Cell interaction and movement in the microenvironment are regulated by CAMs. AKR1B10 upregulated integrin $\alpha 5$, $\delta$-catenin and fibronectin in breast cancer cells. Integrin $\alpha 5$ is a membrane receptor with fibronectin as a ligand, playing a vital role in adhesion and migration of cancer cells [32]; $\delta$-Catenin is upregulated in human cancers and 
promotes tumor metastasis $[15,33]$. This study found that in breast cancer cells, silencing of integrin $\alpha 5$ or $\delta$-catenin alone eradicated the cell adhesion and migration enhanced by AKR1B10; and co-silencing of both integrin $\alpha 5$ and $\delta$-catenin displayed a synergistic effect, suggesting that the integrin $\alpha 5$ and $\delta$-catenin both function as the downstream effectors of AKR1B10 in regulation of the adhesion and migration of breast cancer cells.

\section{A}
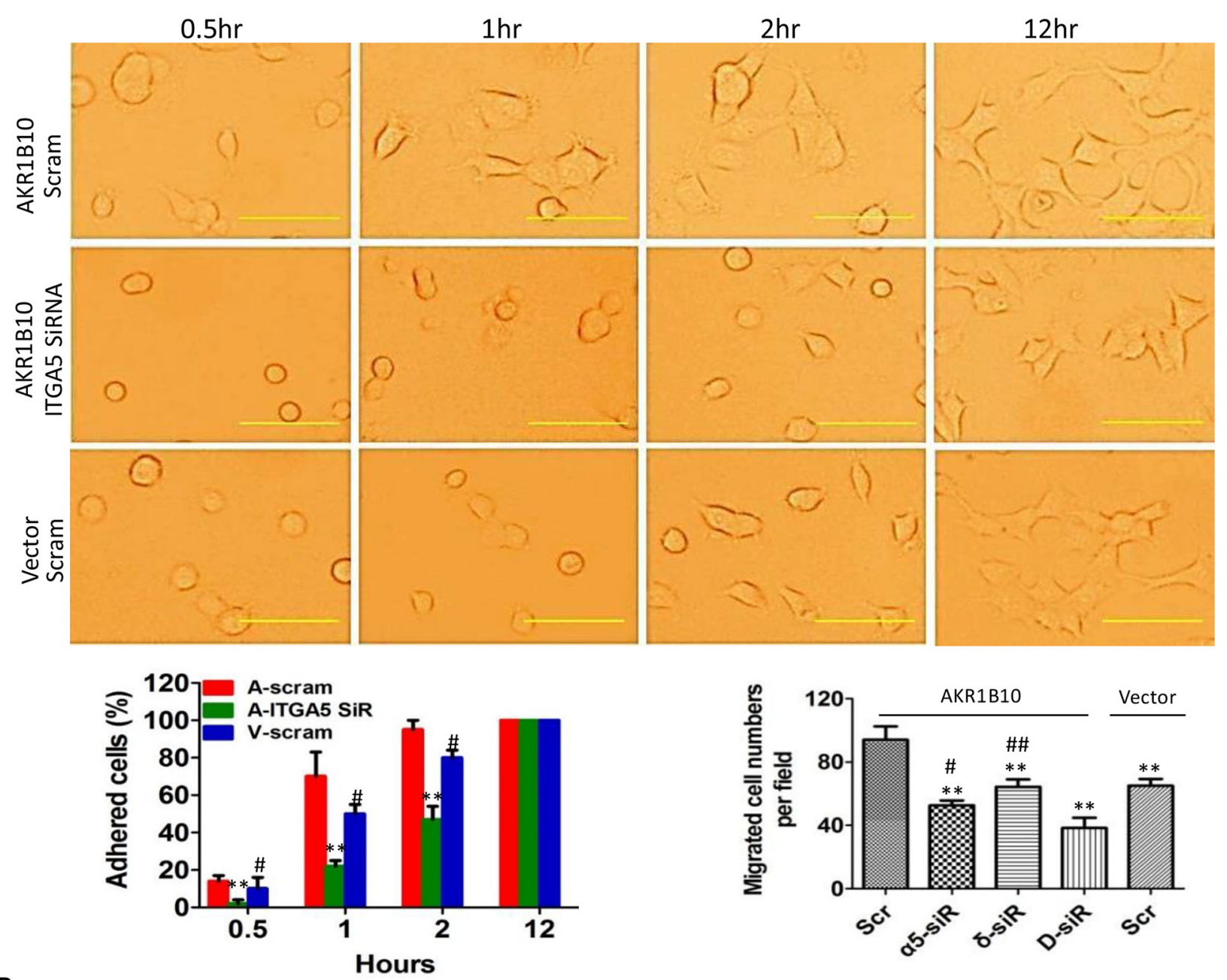

B

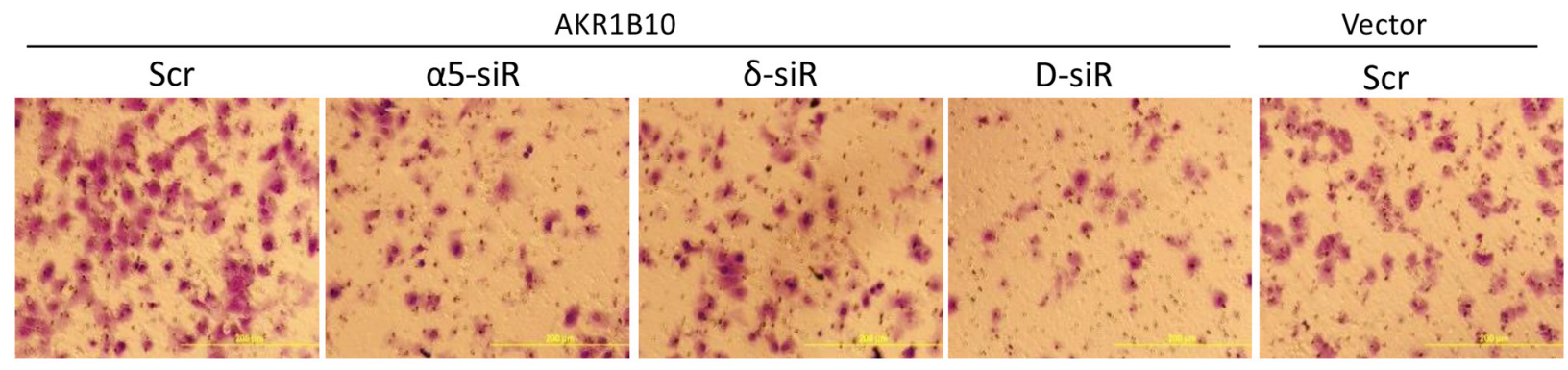

Figure 3: Integrin $\alpha 5$ and $\delta$-catenin mediate the AKR1B10-promoted cell adhesion and migration. A. Cell adhesion. Middle left: quantitation expressed as percentage of adhered cells at each time point over the cells adhered at $12 \mathrm{hours}$. Scale bar $=25 \mu \mathrm{m}$. Data represent mean $\pm \mathrm{SD}$ from three independent assays. ${ }^{* *}, \mathrm{p}<0.01$, compared to A-Scram; \#, $\mathrm{p}<0.05$ and \#\#, $\mathrm{p}<0.01$, compared to A-Scram. A-Scram, AKR1B10 expression MCF-7 cells treated with scramble siRNA; V-Scram, vector control MCF-7 cells treated with scramble siRNA; and A-ITGA5 SiR, AKR1B10 expression MCF-7 cells treated with integrin $\alpha 5$ siRNA. B. Transwell migration of MCF-7 cells with silencing of integrin $\alpha 5, \delta$-catenin, or both. Data represent mean $\pm \mathrm{SD}$ from three independent assays. Middle right: quantitation of migrated cells. Data represent mean $\pm \mathrm{SD}$ from three independent experiments. **, $\mathrm{p}<0.01$ compared to A-Scr control; \#, $<<0.05$ and \#\#, $\mathrm{p}<0.01$ when compared to D-siR. Scr, scrambled siRNA; $\alpha 5$-siR, integrin $\alpha 5$ siRNA; $\delta$-siR, $\delta$-catenin siRNA; and D-siR, double (integrin $\alpha 5$ plus $\delta$-catenin) siRNA. 
How do integrin $\alpha 5$ and $\delta$-catenin mediate the AKR1B10-promoted adhesion and migration of breast cancer cells then? Integrin $\alpha 5$ associates with integrin $\beta 1$ to form an integrin $\alpha 5 \beta 1$ cluster, which recognizes and binds to extracellular fibronectin. The integrin $\alpha 5 \beta 1$-fibronectin complex triggers FA formation and activates focal adhesion kinase (FAK) mediated-signaling pathway $[11,34]$. In this pathway, the activated FAK

A
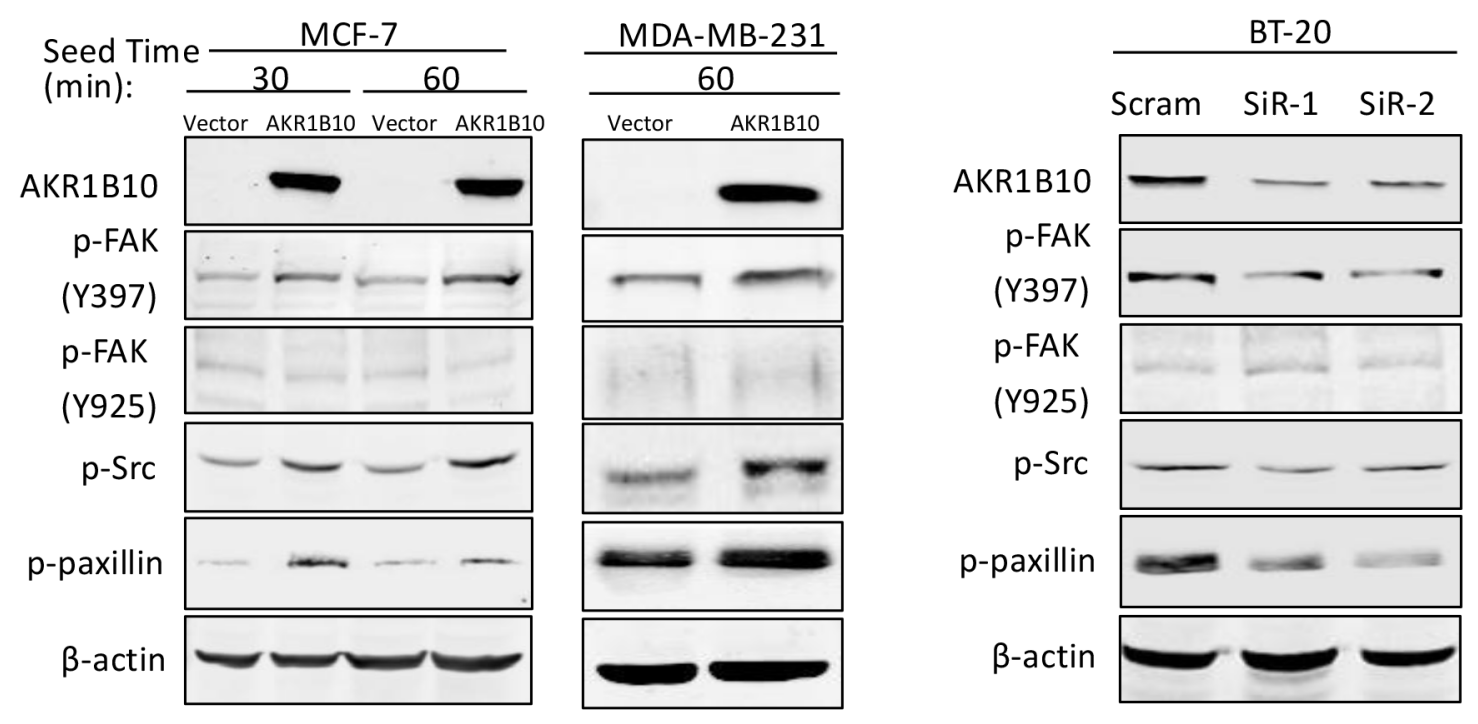

B
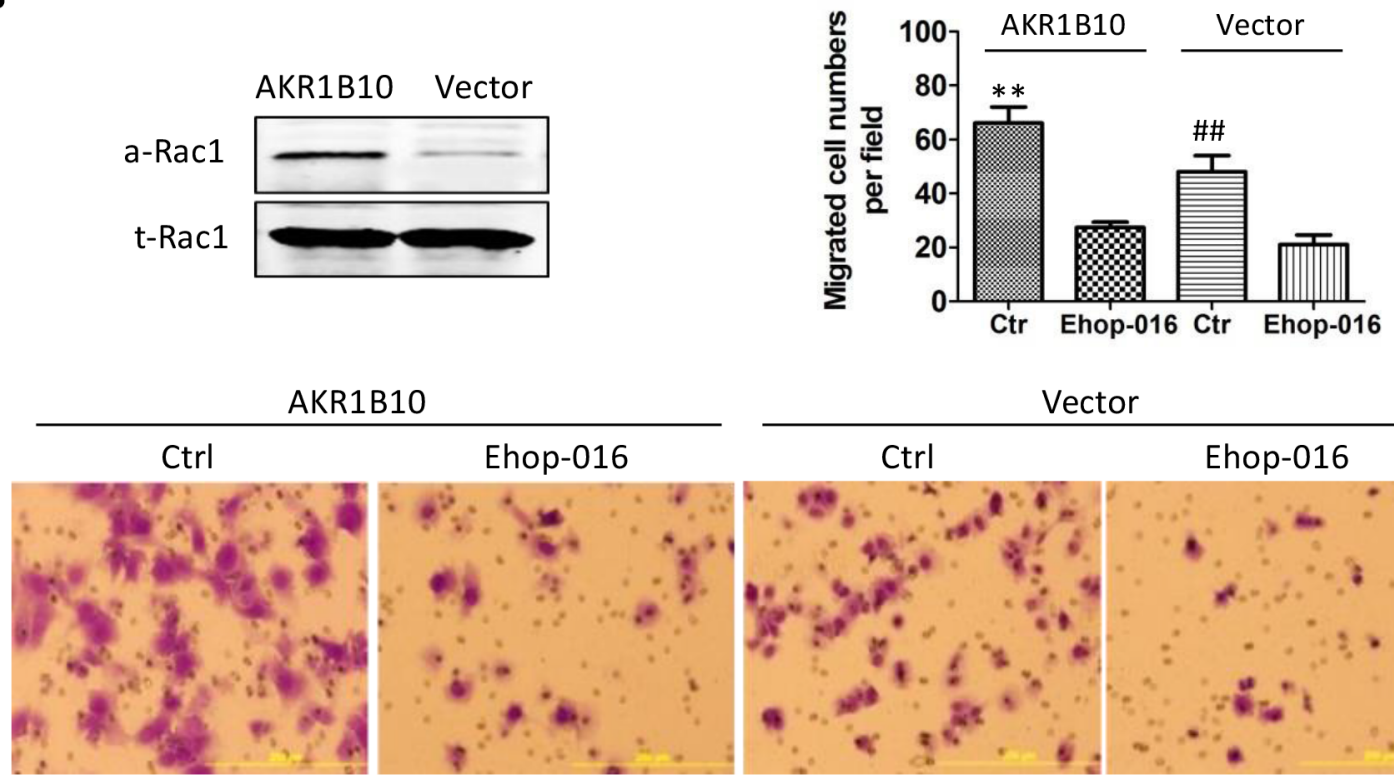

AKR1B10
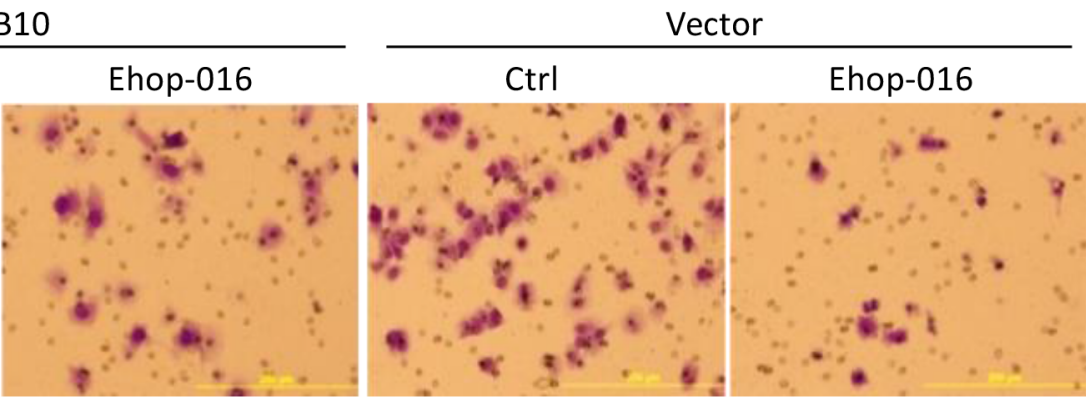

Figure 4: AKR1B10 activates the focal adhesion-Rac1 signaling cascade. A. Activation of focal adhesion signaling cascade, showing p-FAK397, p-FAK925, p-Src and p-paxillin levels in indicated cells. Scram, scrambled siRNA; siR-1, AKR1B10 siRNA-1; siR-2, AKR1B10 siRNA-2. B. Rac1-mediated cell migration. Upper left: Active Rac1 (a-Rac1) examined by pull-down assays with PAK-PBD beads. Active Rac1 pulled down and total Rac1 (t-Rac1) in cell extracts were assessed by Western blot. Lower panel images: Effects of Rac1 inhibitor, EHop-016, on MCF-7 cell Transwell migration. Upper right: Quantitation of migrated cells. Data denote mean \pm SD from three independent experiments. ${ }^{* *} \mathrm{p}<0.01$, compared to EHop-016-treated MCF-7 cells with AKR1B10 expression or with a vector control. \#\# p $<0.01$ compared to EHop-016-treated MCF-7 cells with AKR1B10 expression or with a vector control. 
autophosphorylates its tyrosine-397 residue to recruit and phosphorylate Src kinase, which in turn activates the downstream signaling cascades, such as paxillinRac1 and FAK (pY925)-ERK1/2 [7]. This study showed an increase of phospho-Y397/FAK, phospho-Src, and phospho-paxillin levels and Racl activity, but the phospho-Y925/FAK was not altered, suggesting that the integrin $\alpha 5 \beta 1$-fibronectin complex promotes the adhesion and migration of breast cancer cells through the FA-mediated FAK (pY397)/Src/paxillin/Rac1 signaling pathway, rather than the FAK (pY925)-ERK1/2 cascade. Delta-catenin also regulates the activity of Rho GTPases (e.g., RhoA, Rac1 and Cdc42), promoting lamellipodia protrusion and cell mobility $[33,35]$. The synergistic role of integrin $\alpha 5$ and $\delta$-catenin in the AKR1B10-promoted adhesion and migration of breast cancer cells suggests that Rac1 is a common effector of these two CAMs. To be noted, $\delta$-catenin also binds to E-cadherin and promote cell migration [15]. Our data showed that AKR1B10 did not notably affect the expression, phosphorylation or subcellular distribution of E-cadherin in MCF-7 cells (Supplementary Figure S6), suggesting that $\delta$-catenin acts through the Rac1 rather than E-cadherin signaling.

We further asked how AKR1B10 upregulates integrin $\alpha 5$ and $\delta$-catenin expression. The ERK signaling regulates focal adhesion assembly and disassembly [30]. In this study, we found that the c-Raf/MEK/ ERK signaling cascade was activated by AKR1B10, which may be responsible for upregulation of integrin $\alpha 5$ and $\delta$-catenin as the pharmacological inhibition by MEK1 inhibitors PD98059 $(10 \mu \mathrm{M})$ and U0126 $(10 \mu \mathrm{M})$ attenuated integrin $\alpha 5$ and $\delta$-catenin expression
A
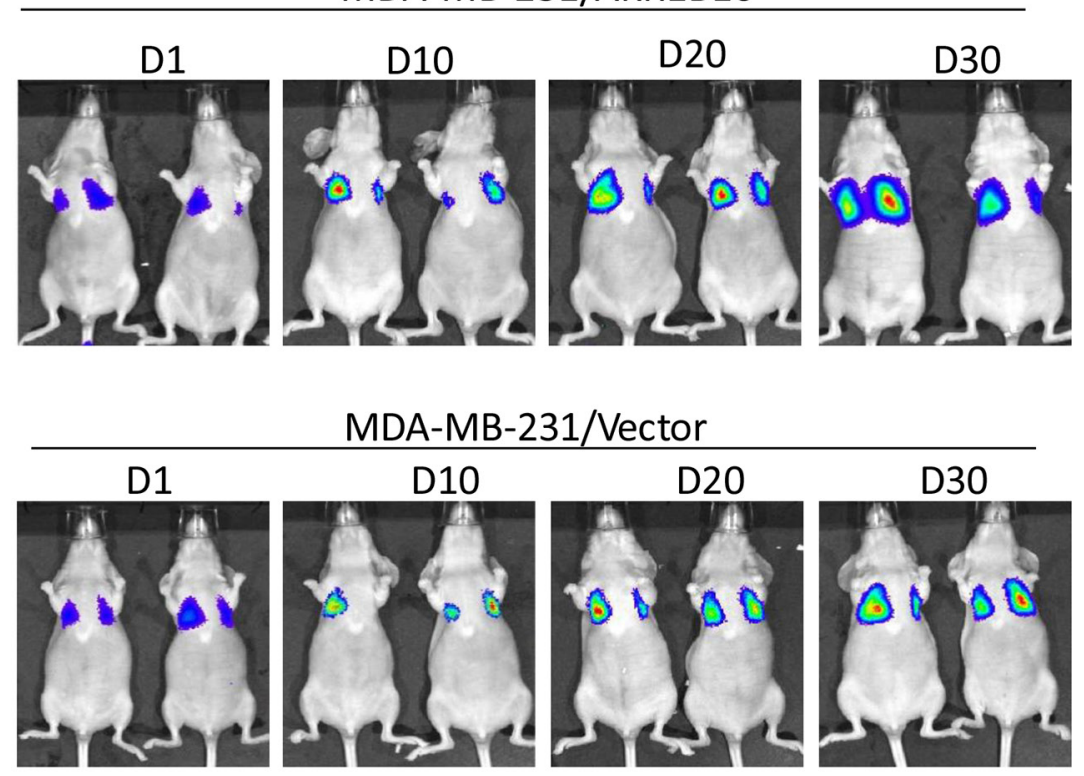

MDA-MB-231/Vector

B

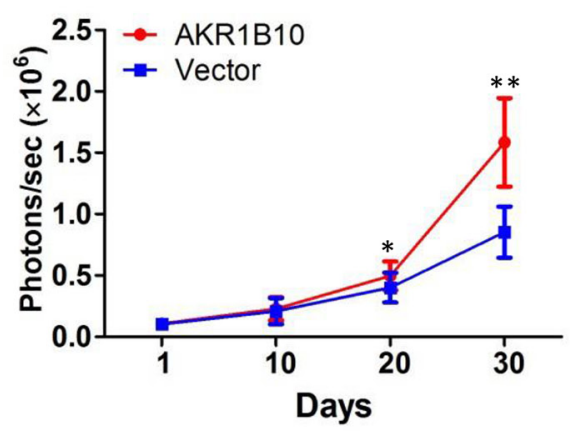

D

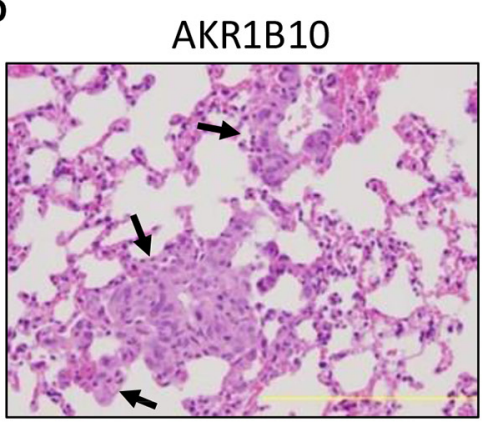

C MDA-MB-231/AKR1B10

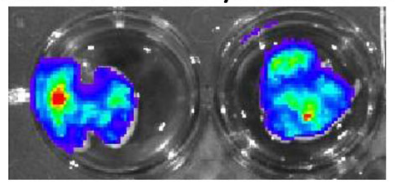

MDA-MB-231/Vector
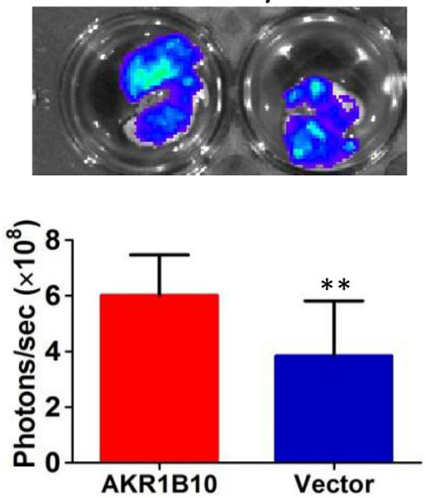

Figure 5: AKR1B10 promotes the lung metastasis of MDA-MB-231 cells in female nude mice. Mice ( $\mathrm{n}=5$ per group) wereinjected via tail vein with MDA-MB-231 cells $\left(1 \times 10^{6}\right)$ labeled with luciferase. A. Bioluminescent images of representative mice at days 1, 10, 20 and 30 post tail vein injection. B. Quantification of bioluminescent strengths at photon/second. C. Ex vivo imaging of lungs. At the end, mice were sacrificed and the lungs were excised for ex vivo bioluminescent imaging. D. H\&E histology of lung metastatic tumors (arrows). Scale bar $=200 \mu \mathrm{m}$. 

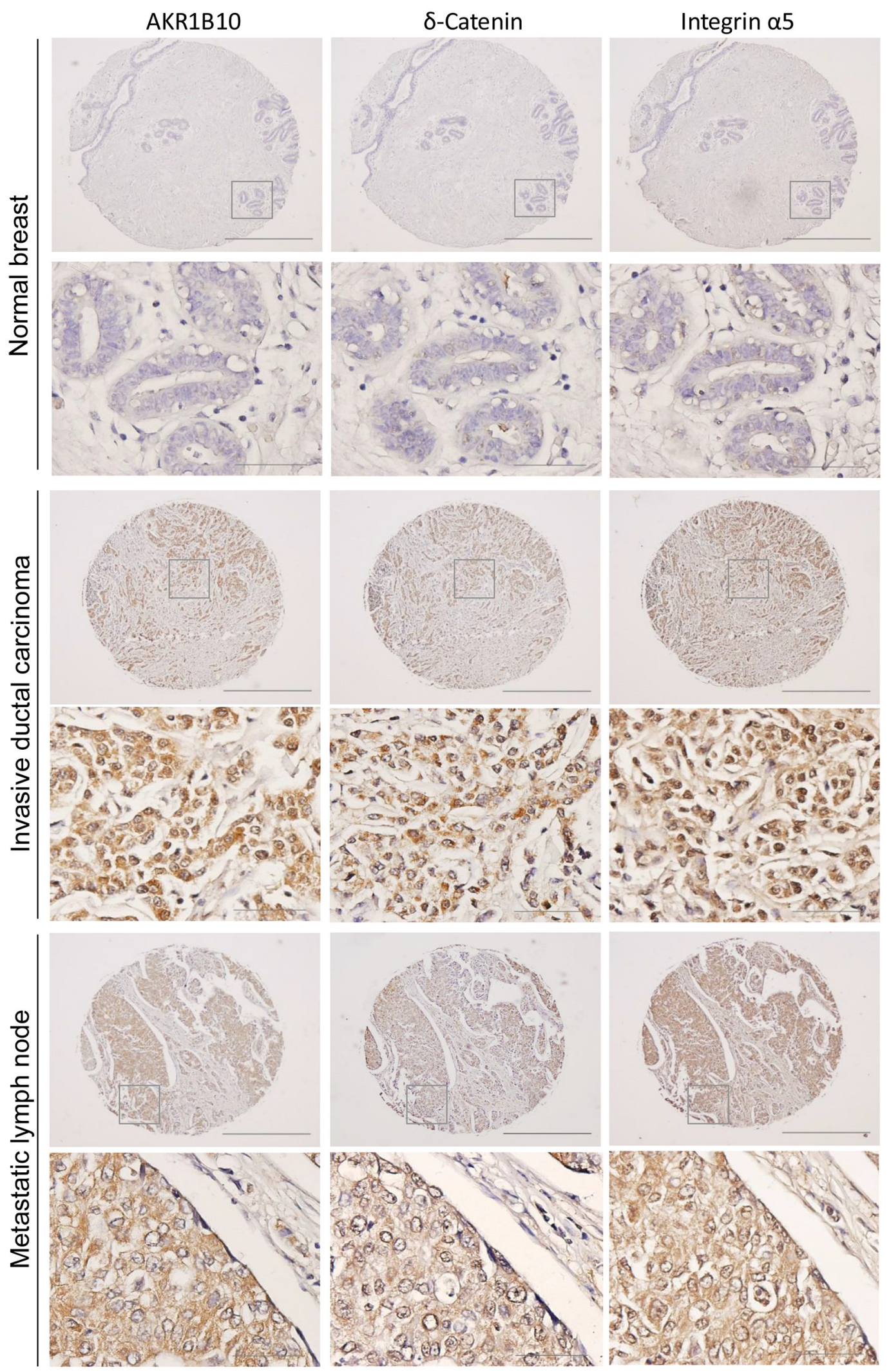

Figure 6: AKR1B10, integrin $\alpha 5$ and $\delta$-catenin are correlatively upregulated in human breast cancer. Adjacent tissue microarrays were stained by immunohistochemistry for the expression of AKR1B10, integrin $\alpha 5$ and $\delta$-catenin in normal breast, primary breast cancer, and lymph node metastatic tumors. The images show representative tissues with these three protein expression. Scale bar $=$ $50 \mu \mathrm{M}(40 \times)$ or $500 \mu \mathrm{M}(4 \times)$. 
Table 1: Expression and correlation of AKR1B10, integrin $\alpha 5$, and $\delta$-catenin in primary and metastatic breast cancers

\begin{tabular}{|c|c|c|c|c|c|c|c|c|}
\hline & \multicolumn{4}{|c|}{ Invasive ductal carcinomas $(\mathbf{N}=\mathbf{5 0})$} & \multicolumn{4}{|c|}{ Metastatic lymph nodes $(\mathrm{N}=40)$} \\
\hline \multicolumn{9}{|c|}{ Expression levels } \\
\hline Intensity & $0(\%)$ & $1(\%)$ & $2(\%)$ & $3(\%)$ & $\mathbf{0}(\%)$ & $1(\%)$ & $2(\%)$ & $3(\%)$ \\
\hline AKR1B10 & $7(14.0)$ & $27(54.0)$ & $11(22.0)$ & $5(10.0)$ & $6(15.0)$ & $18(45.0)$ & $5(12.5)$ & $11(27.5)$ \\
\hline$\delta$-Catenin & $10(20.0)$ & $27(54.0)$ & $8(16.0)$ & $5(10.0)$ & $7(17.5)$ & $18(45.0)$ & $5(12.5)$ & $10(25.0)$ \\
\hline Integrin $\alpha 5$ & $12(24.0)$ & $30(60.0)$ & $5(10.0)$ & $3(6.0)$ & $3(7.5)$ & $23(57.5)$ & $6(15.0)$ & $5(20.0)$ \\
\hline \multicolumn{9}{|c|}{ Correlation } \\
\hline & AKR1B10 & $\delta$-Catenin & Integrin $\alpha 5$ & & & AKR1B10 & $\delta$-Catenin & Integrin $\alpha 5$ \\
\hline AKR1B10 & & $\begin{array}{c}r=0.58785 \\
\mathrm{p}<0.0001\end{array}$ & $\begin{array}{c}r=0.54985 \\
\mathrm{p}<0.0001\end{array}$ & AK & B10 & & $\begin{array}{c}\mathrm{r}=0.69531 \\
\mathrm{p}<0.0001\end{array}$ & $\begin{array}{c}\mathrm{r}=0.74737 \\
\mathrm{p}<0.0001\end{array}$ \\
\hline$\delta$-Catenin & & & $\begin{array}{c}r=0.55669 \\
p<0.0001\end{array}$ & $\delta-C$ & nin & & & $\begin{array}{c}\mathrm{r}=0.65259 \\
\mathrm{p}<0.0001\end{array}$ \\
\hline
\end{tabular}

upregulated by AKR1B10. We do not have yet a direct explanation of how the ERK signaling is activated in these cells. In the FAK-mediated focal adhesion signaling, the phosphorylation of FAK at Y925 could activate the ERK signaling [7], but in the tested cells, the phospho-Y925/FAK level was not altered. In contrast, the phosphorylation level of C-Raf and MEK1/2 was increased, suggesting that the ERK signaling may be activated through a G-protein coupled membrane receptor mechanism. Further study is warranted.

The promoting role of AKR1B10 in breast cancer metastasis was further confirmed in in vivo animal modeling and ex vivo clinical samples. In the female nude mice, AKR1B10 enhanced lung metastasis and nodular growth of MDA-MB-231 cells, demonstrating large metastatic nodules. In clinical specimens of breast cancer, we observed a high correlation in expression between AKR1B10 and integrin $\alpha 5$ and $\delta$-catenin, being supportive to our mechanistic studies in cell culture. Of note, AKR1B10 promoted the adhesion, migration and invasion of MCF-7 cells in vitro, but AKR1B10 alone could not convert the non-invasive MCF-7 cells into invasive, lung metastatic cells (data not shown), suggesting that AKR1B10 may function as a promoter, but not an initiator, of breast cancer metastasis.

In summary, this study demonstrated that AKR1B10 promotes breast cancer metastasis at the levels of in vitro cell culture, in vivo animal and ex vivo clinical settings. This study also demonstrated that AKR1B10 promotes breast cancer metastasis through activation of the integrin $\alpha 5$ and $\delta$-catenin mediated FAK/Src/Rac1 signaling cascade, in which the integrin $\alpha 5$ and $\delta$-catenin function synergistically (Figure 7). Our results suggest that AKR1B10 is a new oncogenic factor in breast cancer metastasis and a potential target for metastatic intervention.

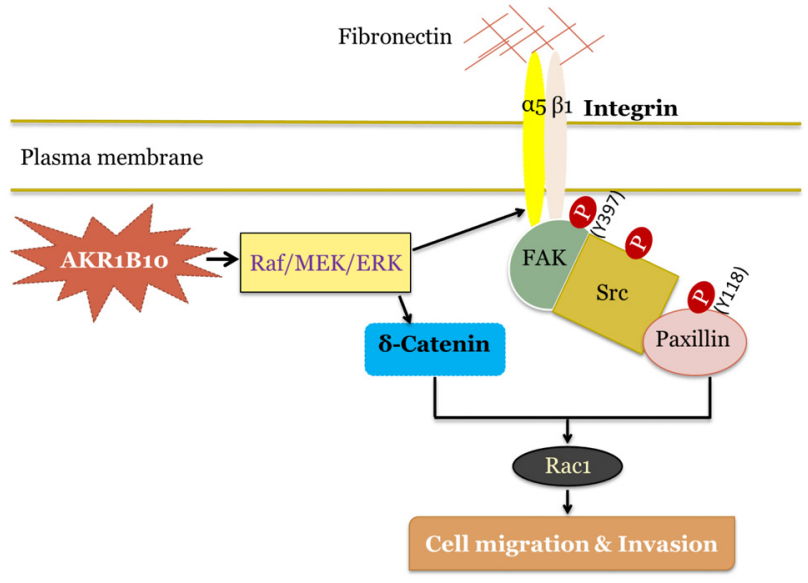

Figure 7: Hypothetic model of AKR1B10 in breast cancer metastasis. AKR1B10 activates Raf/MEK/ERK signaling cascade, which upregulates integrin $\alpha 5$. Integrin $\alpha 5$ associates with integrin $\beta 1$, binds to fibronectin and activates focal adhesion signaling by phosphorylation of focal adhesion kinase (FAK) at residue Y397. Activated FAK provides a platform for Src binding and phosphorylation, which is followed by the activation of Y118-paxillin and Rac1. Meanwhile, AKR1B10-activated Raf/MEK/ERK signaling increases $\delta$-catenin level, which in turn activates Rac1, and synergistically promotes breast cancer cell migration and invasion.

\section{MATERIALS AND METHODS}

\section{Cell culture}

MCF-7, BT-20, MDA-MB-231, and 293T cells purchased from American Type Culture Collection (ATCC, VA) were maintained in indicated medium at 
$37^{\circ} \mathrm{C}, 5 \% \mathrm{CO}_{2}$. For $2 \mathrm{D}$ culture, cells were seeded at 200 cells per $60-\mathrm{mm}$ culture dish and incubated in indicated medium for 14 days; colonies were fixed by methanol (cooled at $-20^{\circ} \mathrm{C}$ ) for $10 \mathrm{~min}$ and visualized by $0.1 \%$ crystal violet. Plating efficiency was calculated as: Colony number/seeded cell number. The 3D culture was done in growth factor-reduced Matrigel (BD Biosciences, CA) [36]. Cells (4000/well) were seeded. Acini were photographed by a phase contrast microscopy (Carl Zeiss, CA).

\section{AKR1B10 ectopic expression}

The full-length AKR1B10 cDNA [16] was inserted into $\mathrm{pCDH}$ lentiviral expression vector with a GFP reporter (System Biosciences, CA). After packaging in $293 \mathrm{~T}$ cells, AKR1B10 and empty pCDH lentiviral particles were introduced into cells with standard procedures. GFP-labeled cells were sorted for a homogeneous population.

\section{AKR1B10, integrin $\alpha 5$ and $\delta$-catenin silencing}

AKR1B10 siRNA previously characterized [20] and integrin $\alpha 5$ and $\delta$-catenin siRNAs (Santa Cruz Biotechnology, CA.) were introduced into cells with scrambled siRNA as a control. Silencing efficiency was evaluated by Western blot analysis.

\section{qRT-PCR}

Total RNA was extracted using Trizol® reagent (Invitrogen, CA) and quantitated at $\mathrm{OD}_{260}$. Total RNA $(1.0 \mu \mathrm{g})$ was treated with RNase-free DNase 1 and reverse-transcribed into cDNA with random primers and Superscript II Rretrotranscriptase (Invitrogen, CA). qRTPCR was run in a mix of $2.0 \mu \mathrm{l}$ cDNA, $10 \mu \mathrm{mol} / \mathrm{L}$ primers and $2 \times$ SYBR Green FastMix (Quanta Biosciences, CA). Relative expression levels were analyzed by comparative $\mathrm{C}_{\mathrm{T}}\left(\Delta \Delta \mathrm{C}_{\mathrm{T}}\right)$ with GAPDH as an internal control. Gene specific primer sequences for qRT-PCR were shown in Supplementary Table S1.

\section{RT $^{2}$ Profiler PCR Array}

Human Extracellular Matrix \& Adhesion Molecules RT ${ }^{2}$ Profiler ${ }^{\mathrm{TM}}$ PCR Array (Qiagen, CA) was used for expression profiling analysis of cell adhesion molecules (CAM). This array simultaneously profiled 84 CAM genes with five housekeeping genes for data normalization.

\section{Western blot}

Protein lysates, SDS-PAGE, and Western blotting was performed as previously described [37].

\section{Cell adhesion assays}

The 96-well plates (Thermo Scientific, IL) were coated with $100 \mu \mathrm{l}$ of $10 \mu \mathrm{g} / \mathrm{ml}$ fibronectin, collagen, laminin or gelatin (BD Biosciences, CA) at $37^{\circ} \mathrm{C}$ for 1 hour, followed by blocking with $1 \%$ BSA for 45 minutes. Serum-starved cells were suspended with $2.0 \mathrm{mM}$ EDTA, and spread at $5 \times 10^{4}$ cells per well in $100 \mu$ medium containing 1\% FBS. After incubation for 30, 60 or 120 minutes at $37^{\circ} \mathrm{C}, 5 \% \mathrm{CO}_{2}$, attached cells were fixed with $4 \%$ paraformaldehyde and stained with $0.2 \%$ crystal violet in $10 \%$ ethanol for quantitation at $570 \mathrm{~nm}$ using a Multiscan Spectrum reader (Thermo Scientific, IL).

\section{Cell migration, invasion and wound-healing assays}

Migration assays were performed using Boyden chamber Transwells with $8 \mu \mathrm{m}$ pore size membrane (Costar, MA) that were coated with $10 \mu \mathrm{g} / \mathrm{ml}$ fibronectin in PBS at $4^{\circ} \mathrm{C}$ overnight. Cells $\left(5 \times 10^{4}-8 \times 10^{4} /\right.$ well $)$ were placed in the upper chamber. After 24 hours, cells in the inner surface of inserts were removed by cotton swabs and the cells on the outer surface of the inserts were fixed, stained and counted under a microscope (Olympus, Japan). Cell invasion was assayed in matrigel-coated Boyden chambers. Cells $\left(5 \times 10^{4} /\right.$ well $)$ were added onto the top of chamber. After 48 hours, cells were fixed, stained and counted. For Rac1 inhibition, cells were exposed to a Rac1 inhibitor, Ehop-016 (Sigma, MO) at $2 \mu \mathrm{M}$ for 24 hours and then seeded into Boyden chamber. For wound-healing assays, a linear scratch was created in monolayer cells using a $200 \mu \mathrm{l}$ pipette tip and the healing was monitored under a microscopy (Olympus, Japan).

\section{Rac1 activity assay}

Rac1 activity was measured by a Rac1 assay kit (Cytoskeleton, CO) according to the manufacturer protocol. Cells were allowed to adhere to fibronectincoated plates for 60 minutes in the medium containing $1 \%$ FBS before assays.

\section{Lung metastasis}

The luciferase-labeled MDA-MB-231 cells $\left(1 \times 10^{6}\right.$ in $100 \mu \mathrm{l}$ of PBS) that express AKR1B10 or vector control were injected into the tail vein of 5-week-old female BALB/c nude mice. In vivo lung bioluminescent imaging was conducted using an IVIS-200 Imaging System (Caliper Life Sciences, MA) to monitor metastatic tumors for 5 weeks. Bioluminescence was quantified as total photon/s using Living Image software (Caliper Life Sciences, MA). For ex vivo lung imaging, $200 \mu \mathrm{l}$ of D-luciferin $(150 \mathrm{mg} / \mathrm{kg}$ in PBS) was injected intraperitoneally, and mice were euthanized. Lungs were 
excised and imaged for 1-3 seconds in 12-well plates containing $300 \mu \mathrm{g} / \mathrm{ml}$ D-luciferin in PBS [38]. Thereafter, the lungs were sliced and fixed in $10 \%$ formalin for histology.

\section{Tissue microarrays}

Adjacent breast cancer tissue microarrays containing 50 invasive carcinomas, 40 lymph node metastatic tumors and 10 adjacent normal tissues were purchased from US Biomax (Rockville, MD). Standard immunohistochemistry [25] was performed for AKR1B10, integrin $\alpha 5$, or $\delta$-catenin expression.

\section{Statistical analysis}

Statistical analyses were performed using Student's $t$ tests with INSTAT statistical analysis package (Graph Pad software, CA). Significance was defined as $p<0.05$. Correlation analyses were conducted using Spearman correlation and multivariate canonical correlation.

\section{CONFLICTS OF INTEREST}

All authors declare no conflict of interest.

\section{GRANT SUPPORT}

This work was supported in part by National Natural Science Foundation of China (81272918 and 81472465 for DC) and by Avon Foundation (Avon 02-2014-049 for KR and DC). Animal studies were supported by internal funding in SIU School of Medicine.

\section{REFERENCES}

1. Siegel R, Ma J, Zou Z and Jemal A. Cancer statistics, 2014. CA: a cancer journal for clinicians. 2014; 64:9-29.

2. Cardoso F, Fallowfield L, Costa A, Castiglione M, Senkus E and Group EGW. Locally recurrent or metastatic breast cancer: ESMO Clinical Practice Guidelines for diagnosis, treatment and follow-up. Annals of oncology. 2011; 22:vi25-30.

3. Chambers AF, Groom AC and MacDonald IC. Dissemination and growth of cancer cells in metastatic sites. Nat Rev Cancer. 2002; 2:563-572.

4. Vicente-Manzanares M, Webb DJ and Horwitz AR. Cell migration at a glance. Journal of cell science. 2005; 118:4917-4919.

5. Campbell ID and Humphries MJ. Integrin structure, activation, and interactions. Cold Spring Harb Perspect Biol. 3.

6. Bendas $\mathrm{G}$ and Borsig L. Cancer cell adhesion and metastasis: selectins, integrins, and the inhibitory potential of heparins. Int J Cell Biol. 2012:676731.
7. Hood JD and Cheresh DA. Role of integrins in cell invasion and migration. Nat Rev Cancer. 2002; 2:91-100.

8. Nagano M, Hoshino D, Koshikawa N, Akizawa T and Seiki M. Turnover of focal adhesions and cancer cell migration. Int J Cell Biol. 2012:310616.

9. Faix $\mathrm{J}$ and Weber I. A dual role model for active Rac1 in cell migration. Small GTPases. 4:110-115.

10. Desgrosellier JS and Cheresh DA. Integrins in cancer: biological implications and therapeutic opportunities. Nat Rev Cancer. 10:9-22.

11. Wang QY, Zhang Y, Shen ZH and Chen HL. alpha1,3 fucosyltransferase-VII up-regulates the mRNA of alpha5 integrin and its biological function. J Cell Biochem. 2008; 104:2078-2090.

12. Nam JM, Onodera Y, Bissell MJ and Park CC. Breast cancer cells in three-dimensional culture display an enhanced radioresponse after coordinate targeting of integrin alpha5beta1 and fibronectin. Cancer Res. 70:5238-5248.

13. Ricart AD, Tolcher AW, Liu G, Holen K, Schwartz G, Albertini M, Weiss G, Yazji S, Ng C and Wilding G. Volociximab, a chimeric monoclonal antibody that specifically binds alpha5beta1 integrin: a phase I, pharmacokinetic, and biological correlative study. Clinical cancer research. 2008; 14:7924-7929.

14. Ho C, Zhou J, Medina M, Goto T, Jacobson M, Bhide PG and Kosik KS. delta-catenin is a nervous system-specific adherens junction protein which undergoes dynamic relocalization during development. J Comp Neurol. 2000; 420:261-276.

15. Lu Q. delta-Catenin dysregulation in cancer: interactions with E-cadherin and beyond. J Pathol. 222:119-123.

16. Cao D, Fan ST and Chung SS. Identification and characterization of a novel human aldose reductaselike gene. The Journal of biological chemistry. 1998; 273:11429-11435.

17. Zhong L, Liu Z, Yan R, Johnson S, Zhao Y, Fang X and Cao D. Aldo-keto reductase family $1 \mathrm{~B} 10$ protein detoxifies dietary and lipid-derived alpha, beta-unsaturated carbonyls at physiological levels. Biochemical and biophysical research communications. 2009; 387:245-250.

18. Zu X, Yan R, Robbins S, Krishack PA, Liao DF and Cao D. Reduced 293T cell susceptibility to acrolein due to aldose reductase-like-1 protein expression. Toxicological sciences. 2007; 97:562-568.

19. Shen Y, Zhong L, Johnson S and Cao D. Human aldoketo reductases $1 \mathrm{~B} 1$ and 1B10: A comparative study on their enzyme activity toward electrophilic carbonyl compounds. Chemico-biological interactions. 2011; 191:192-198

20. Yan R, Zu X, Ma J, Liu Z, Adeyanju M and Cao D. Aldoketo reductase family $1 \mathrm{~B} 10$ gene silencing results in growth inhibition of colorectal cancer cells: Implication for cancer intervention. International journal of cancer Journal international du cancer. 2007; 121:2301-2306. 
21. Shen Y, Zhong L, Markwell S and Cao D. Thiol-disulfide exchanges modulate aldo-keto reductase family 1 member B10 activity and sensitivity to inhibitors. Biochimie. 2010; 92:530-537.

22. Ma J, Yan R, Zu X, Cheng JM, Rao K, Liao DF and Cao D. Aldo-keto reductase family 1 B10 affects fatty acid synthesis by regulating the stability of acetyl-CoA carboxylase-alpha in breast cancer cells. The Journal of biological chemistry. 2008; 283:3418-3423.

23. Wang C, Yan R, Luo D, Watabe K, Liao DF and Cao D. Aldo-keto reductase family 1 member B10 promotes cell survival by regulating lipid synthesis and eliminating carbonyls. The Journal of biological chemistry. 2009; 284:26742-26748.

24. Luo DX, Huang MC, Ma J, Gao Z, Liao DF and Cao D. Aldo-keto reductase family 1 , member B10 is secreted through a lysosome-mediated non-classical pathway. The Biochemical journal. 2011; 438:71-80.

25. Shen Y, Ma J, Yan R, Ling H, Li X, Yang W, Gao J, Huang C, Bu Y, Cao Y, He Y, Wan L, Zu X, Liu J, Huang MC, Stenson WF, et al. Impaired Self-Renewal and Increased Colitis and Dysplastic Lesions in Colonic Mucosa of AKR1B8-Deficient Mice. Clinical cancer research. 2015; 21:1466-1476.

26. Li Z, He X, Xing S, Ni J, Zhang W, Xu X, Gao F, Gai J, Zhao Z, Li J, Gong P, Zhang G and Zhang X. Overexpression of Aldo-keto reductase family 1 B10 protein in ductal carcinoma in situ of the breast correlates with HER2 positivity. Cancer Biomark. 13:181-192.

27. Ma J, Luo DX, Huang C, Shen Y, Bu Y, Markwell S, Gao J, Liu J, Zu X, Cao Z, Gao Z, Lu F, Liao DF and Cao D. AKR1B10 overexpression in breast cancer: association with tumor size, lymph node metastasis and patient survival and its potential as a novel serum marker. International journal of cancer Journal international du cancer. 2012; 131:E862-871.

28. Liu Z, Yan R, Al-Salman A, Shen Y, Bu Y, Ma J, Luo DX, Huang C, Jiang Y, Wilber A, Mo YY, Huang MC, Zhao Y and $\mathrm{Cao}$ D. Epidermal growth factor induces tumour marker AKR1B10 expression through activator protein-1 signalling in hepatocellular carcinoma cells. The Biochemical journal. 2012; 442:273-282.

29. Fukumoto S, Yamauchi N, Moriguchi H, Hippo Y, Watanabe A, Shibahara J, Taniguchi H, Ishikawa S, Ito H, Yamamoto
S, Iwanari H, Hironaka M, Ishikawa Y, Niki T, Sohara Y, Kodama T, et al. Overexpression of the aldo-keto reductase family protein AKR1B10 is highly correlated with smokers' non-small cell lung carcinomas. Clinical cancer research. 2005; 11:1776-1785.

30. Webb DJ, Donais K, Whitmore LA, Thomas SM, Turner CE, Parsons JT and Horwitz AF. FAK-Src signalling through paxillin, ERK and MLCK regulates adhesion disassembly. Nature cell biology. 2004; 6:154-161.

31. Berrier AL, Martinez R, Bokoch GM and LaFlamme SE. The integrin beta tail is required and sufficient to regulate adhesion signaling to Rac1. Journal of cell science. 2002; 115:4285-4291.

32. Schaffner F, Ray AM and Dontenwill M. Integrin alpha5beta1, the Fibronectin Receptor, as a Pertinent Therapeutic Target in Solid Tumors. Cancers (Basel). 5:27-47.

33. Abu-Elneel K, Ochiishi T, Medina M, Remedi M, Gastaldi L, Caceres A and Kosik KS. A delta-catenin signaling pathway leading to dendritic protrusions. The Journal of biological chemistry. 2008; 283:32781-32791.

34. Qin L, Chen X, Wu Y, Feng Z, He T, Wang L, Liao L and $\mathrm{Xu}$ J. Steroid receptor coactivator-1 upregulates integrin alpha expression to promote breast cancer cell adhesion and migration. Cancer Res. 71:1742-1751.

35. Kim H, Han JR, Park J, Oh M, James SE, Chang S, Lu Q, Lee KY, Ki H, Song WJ and Kim K. Delta-catenininduced dendritic morphogenesis. An essential role of p190RhoGEF interaction through Akt1-mediated phosphorylation. The Journal of biological chemistry. 2008; 283:977-987.

36. Debnath J, Muthuswamy SK and Brugge JS. Morphogenesis and oncogenesis of MCF-10A mammary epithelial acini grown in three-dimensional basement membrane cultures. Methods. 2003; 30:256-268.

37. Cao Z, Ma J, Chen X, Zhou B, Cai C, Huang D, Zhang $\mathrm{X}$ and Cao D. Uridine homeostatic disorder leads to DNA damage and tumorigenesis. Cancer letters. 2016; 372:219-225.

38. Jenkins DE, Hornig YS, Oei Y, Dusich J and Purchio T. Bioluminescent human breast cancer cell lines that permit rapid and sensitive in vivo detection of mammary tumors and multiple metastases in immune deficient mice. Breast Cancer Res. 2005; 7:R444-454. 